\title{
Feasibility, acceptability, and effectiveness of family- based treatment for adolescent anorexia nervosa: an observational study conducted in Brazil
}

\section{Viabilidade, aceitação e eficácia do tratamento familiar para anorexia nervosa em adolescentes: um estudo observacional no Brasil}

\author{
Gizela Turkiewicz, ${ }^{1}$ Vanessa Pinzon, ${ }^{1}$ James Lock, ${ }^{2}$ Bacy Fleitlich-Bilyk ${ }^{3}$ \\ ${ }^{1}$ Institute of Psychiatry, Universidade de São Paulo (USP), São Paulo, SP, Brazil \\ ${ }^{2}$ Stanford Child and Adolescent Eating Disorder Program, Division of Child Psychiatry, Department of Psychiatry and Behavioral Sciences, \\ Stanford University, USA \\ ${ }^{3}$ Eating Disorders Outpatient and Inpatient Program, Child and Adolescent Psychiatry Division, Institute of Psychiatry, Universidade de \\ São Paulo (USP), São Paulo, SP, Brazil \\ Eating Disorders Outpatient and Inpatient Program, Child and Adolescent Psychiatry Division (PROTAD/SEPIA), Department of Psychiatry, \\ Institute of Psychiatry, Universidade de São Paulo (USP), São Paulo, SP, Brazil
}

\begin{abstract}
Objective: There is strong evidence that family-based treatment is effective in cases of adolescent anorexia nervosa. Although family-based treatment has been studied in English-speaking countries, there is a need to examine the generalizability of this approach to non-English speaking cultures. This pilot-study aimed to examine the feasibility, acceptability, and effectiveness of family-based treatment in Brazil. Method: Observational study of adolescents with anorexia nervosa (excluding menstrual criteria), as determined with the Diagnostic and Well-Being Assessment, referred for treatment at a specialized center in São Paulo, Brazil. The following data were collected at baseline, at the end of treatment, and after six months of follow-up: weight; height; body mass index; menstrual status; Eating Disorder Examination Questionnaire score; and Children Global Assessment of Functioning Scale score. Results: Of 11 eligible patients/families, 9 (82\%) enrolled in the study, and $7(78 \%)$ completed the treatment. The mean patient age was $14.64 \pm 1.63$ years (range, $12.33-17.00$ years). The Wilcoxon signed rank test showed statistically significant improvement in weight and body mass index at the end of treatment, as well as after six months of follow-up, at which point none of the patients met the diagnostic criteria for any eating disorder. Conclusion: The results suggest that family-based treatment is acceptable and feasible for Brazilian families. Outcomes suggest that the approach is effective in this cultural context, leading to improvements similar to those reported in previous studies conducted in other cultures.
\end{abstract}

Descriptors: Anorexia nervosa; Family therapy; Adolescents; Evidencebased practice; Treatment outcome

\section{Resumo}

Objetivo: Estudos prévios demonstram fortes evidências de eficácia do Tratamento Familiar para anorexia nervosa em adolescentes. Os estudos disponiveis a respeito do tratamento familiar foram conduzidos em paises de língua inglesa. É necessário avaliar a aplicabilidade deste método em países de lingua não-inglesa. Este estudo piloto tem como objetivo avaliar a viabilidade, a aceitação e a eficácia do tratamento familiar no Brasil. Método: Estudo observacional de adolescentes com diagnóstico anorexia nervosa (exceto critério amenorréia) segundo o Levantamento sobre Diagnóstico e BemEstar de crianças e adolescentes encaminhadas para tratamento em um centro especializado na cidade de São Paulo, Brasil. Dados coletados no início do estudo, ao final do tratamento e seis meses após o término: peso, estatura, indice de massa corporal, menstruações, Questionário de Exame para Transtornos Alimentares e Escala de Funcionamento Global para Crianças. Resultados: Nove de 11 familias elegiveis entraram no estudo (82\%) e sete (78\%) completaram o tratamento. A idade média foi 14,64 anos $(D P=1,63 ; 12,33-17,00)$. Teste dos sinais de Wilcoxon demonstrou melhora estatisticamente significativa no peso e indice de massa corporal ao final do tratamento e seis meses após o término. Nenhum dos pacientes preencheu critérios diagnósticos para qualquer transtorno alimentar no seguimento. Conclusão: Os resultados sugerem que tratamento familiar é aceitável e viável para as familias brasileiras. A evolução sugere que este método pode ser eficaz nesse contexto cultural com resultados positivos semelhantes a estudos prévios realizados em outras culturas.

Descritores: Anorexia nervosa; Terapia familiar; Adolescentes; Prática médica baseada em evidências; Resultado de tratamento
Submitted: July 29, 2009

Accepted: October 6, 2009
Correspondence

Gizela Turkiewicz

Rua Haddock Lobo, 846, cj1102B - Jd. Paulista

01414-000 São Paulo, SP, Brasil

Fax: (11) 3562-1207

E-mail: giturkiewicz@yahoo.com.br 


\section{Introduction}

Anorexia nervosa $(\mathrm{AN})$ is a serious psychiatric disorder with a prevalence rate of $0.3 \%$ in adolescent females. ${ }^{1} \mathrm{AN}$ is associated with a high mortality rate and is often complicated by psychiatric and medical comorbidity. The accumulated evidence supports the hypothesis that outcomes are better when adolescent patients and their parents are treated together. Studies suggest that family-based treatment (FBT), a method developed and described in a manual written specifically for AN by Lock (J.L.), is an effective treatment for AN..$^{2-4}$ However, those studies were all conducted in Englishspeaking countries. The purpose of the current study is to examine the feasibility, acceptability, and effectiveness of this approach in Brazil.

To date, there have been no studies examining FBT for AN in Brazil. Specialized clinical treatment for adolescent AN in Brazil in public care is limited to a multidisciplinary program either as an inpatient or outpatient in the hospital where this study was conducted and other outpatient programs in university hospitals. The alternative is treatment at private clinics, which are not accessible for most of the population. There is a need to examine treatment alternatives for AN in Brazil because of high costs, long waiting lists, and limited public resources. For example, the estimated average waiting time for treatment in a specialized center has been shown to be 22 months per patient. ${ }^{5}$ There is evidence that the duration of $\mathrm{AN}$ is associated with greater morbidity and resistance to treatment, early intervention apparently leading to better outcomes. ${ }^{2}$ Therefore, FBT might be a cost-effective alternative for the outpatient treatment of Brazilian adolescents with AN.

\section{Method}

Over a three-month period, eligible patients were identified from consecutive referrals to a multidisciplinary outpatient program specialized in treating adolescent eating disorders at a public hospital in the city of São Paulo, Brazil. The study was approved by the research ethics committee of the institution (0801/08). Written informed consent was obtained from parents or legal guardians. Eligibility was accessed during the first psychiatric evaluation of the patients, prior to any specialized intervention. Subjects were eligible to enroll in the study if they were $\leq 17$ years of age, lived with at least one parent or legal guardian, and had been diagnosed with AN, based on the DSM-IV-TR (excluding the menstruation criterion). Subjects were excluded if presenting other psychiatric disorders that required immediate treatment (e.g., suicide threat) or requiring acute hospitalization for medical stabilization. The diagnosis of AN was established by trained interviewers using the Development and Well-being Assessment-Brazilian version. ${ }^{6,7}$ In addition, we collected pre-treatment, post-treatment, and six-month follow-up data on the following variables: weight; height; body mass index (BMI); and menstrual status. The selfreport version of the Eating Disorder Examination, known as the Eating Disorder Examination-Questionnaire (EDE-Q) ${ }^{8,9}$ and the Children's Global Assessment Scale (CGAS) ${ }^{10}$ were applied at all assessment points. A target weight range was defined based on individual pre-weight loss percentiles on the National Center for Health Statistics (NCHS) BMI-for-age growth chart. For patients who were overweight before the onset of the disorder, the target weight was set between the $25^{\text {th }}$ and $50^{\text {th }}$ percentiles on the same chart. ${ }^{11}$

The treatment used in the study was FBT for AN, in accordance with the guidelines established in the manual. ${ }^{4}$ Prior to starting the study, therapists were trained in FBT in a workshop conducted by an expert, the first author of the manual. The study therapists (one psychiatrist and three psychologists) were supervised on a weekly basis by the principal investigator of this study and, online, by the first author of the manual. The FBT method applied in this study consisted of 10-12 family sessions over a six-month period. ${ }^{12}$ FBT is sub-divided into three phases. In phase I, parents are coached by the therapist to take over control of weight restoration of their child. In phase II, once weight restoration is achieved, parents gradually return the control of eating and weight to the adolescent. Phase III briefly addresses adolescent developmental issues and termination of treatment.

The statistical analysis was carried out with the Statistical Package for the Social Sciences, version 14.0 (SPSS, Inc., Chicago, IL, USA). Descriptive statistics were performed in order to analyze the frequencies of the following variables: age; ethnicity; type of family; number of family members; and number of siblings. Nonparametric tests were performed in order to compare variables in the same patient at all assessments points. The Wilcoxon signed rank test for related samples was used in order to determine variations in weight, BMI, and CGAS score, as well as EDE-Q global score and restraint subscale score, between assessment points. McNemar's test was performed in order to compare menstrual status between assessment points.

\section{Results}

Over a three-month period, eleven participants were recruited for the study. None had received specialized treatment for AN before this study. Two patients were excluded between the recruitment and treatment phases, one due to the unavailability of the whole family to attend the sessions and the other because she required hospital admission for medical instability. Therefore, nine patients were enrolled in the study. Of those nine, one was referred to inpatient treatment after the first session due to medical instability and the family of another declined to participate beyond the first session. Therefore, only seven (78\%) of the nine completed the treatment. Among the seven who completed FBT, the median number of sessions was $11 \pm 1.11$ (range, 9-12), distributed over a mean period of $5.7 \pm 1.38$ months (range, 4-7 months).

The mean age of the patients who enrolled in the study was $14.64 \pm 1.63$ years (range, 12.33-17.00 years). Seven (78\%) were White, seven (78\%) were from intact families, and eight (89\%) had at least one sibling. Comorbid depression or anxiety was present in five patients (56\%). Those five patients received concomitant treatment with antidepressants, which were started before the FBT was initiated. 
Table 1 - Outcomes after treatment and at the end of the 6-month follow-up period

\begin{tabular}{lccccc}
\hline \multicolumn{1}{c}{ Variable } & Baseline & End of FBT & $\mathbf{p}^{*}$ & End of follow-up & $\mathbf{p}^{*}$ \\
\hline Weight $(\mathrm{kg})$ & $43.31 \pm 7.57$ & $50.48 \pm 11.22$ & $0.036^{* *}$ & $55.85 \pm 13.20$ & $0.012^{* * *}$ \\
BMI $\left(\mathrm{kg} / \mathrm{m}^{2}\right)$ & $16.39 \pm 1.69$ & $19.04 \pm 3.34$ & $0.036^{* *}$ & $20.80 \pm 3.47$ & $0.012^{* * *}$ \\
EDE-Q global score & $2.81 \pm 1.44$ & $1.69 \pm 2.01$ & $0.176^{* *}$ & $1.22 \pm 1.73$ & $0.069^{* \star *}$ \\
CGAS score & $54.75 \pm 8.61$ & $69.13 \pm 21.52$ & $0.207^{* *}$ & $80.75 \pm 10.56$ & $0.012^{* * *}$ \\
\hline
\end{tabular}

$B M I=$ body mass index; $E D E-Q=$ Eating Disorder Examination-Questionnaire; $C G A S=$ Children's

Global Assessment Scale; FBT = family-based treatment

Data expressed as mean $\pm S D$.

* Wilcoxon signed rank test

** end of FBT vs. baseline

${ }^{* * *}$ end of follow-up vs. baseline

At baseline, the mean weight of the participants was $43.31 \pm 7.57 \mathrm{~kg}$ (range 32.8-49.3kg), and the mean BMI was $16.39 \pm 1.69 \mathrm{~kg} / \mathrm{m}^{2}$ (range, $13.83-18.89 \mathrm{~kg} / \mathrm{m}^{2}$ ). The BMI percentiles, according to the NCHS growth charts, were all below the $25^{\text {th }}$ percentile. ${ }^{11}$ At the end of the FBT, the mean weight was $50.5 \mathrm{~kg}(\mathrm{SD}=11.22 \mathrm{~kg}$ (range, 34.3-68.5 kg), the mean BMI was $19.0 \pm 3.3 \mathrm{~kg} / \mathrm{m}^{2}$ (range, $\left.14.4-22.9 \mathrm{~kg} / \mathrm{m}^{2}\right)$. By the end of treatment, six $(86 \%)$ of the seven patients who completed the treatment had achieved the target weight. At follow-up, the mean weight was $55.9 \pm 13.2 \mathrm{~kg}$ (range, $42-85 \mathrm{~kg}$ ), the mean BMI was $20.8 \pm 3.5 \mathrm{~kg} / \mathrm{m}^{2}$; range, $\left.17.6-28.4 \mathrm{~kg} / \mathrm{m}^{2}\right)$. The Wilcoxon signed rank test showed statistically significant increases in weight from baseline to the end of treatment $(Z=-2.100$, $\mathrm{p}=0.036)$ and from baseline to the end of follow-up $(Z=-2.521$, $\mathrm{p}=0.012$ ). Similar statistically significant changes were found in BMI at these assessment points (Table 1).

At first evaluation, eight (89\%) of the patients had amenorrhea. At the end of treatment, four (44\%) had regular menses, whereas all of the patients evaluated had regular menses at the end of followup. When McNemar's test was applied, a significant improvement in menstrual status was found when comparing baseline to the end of follow-up ( $\mathrm{p}=0.016)$. The mean EDE-Q global score was $2.81 \pm 1.44$ (range, $0.27-4.51$ ) before treatment, $1.69 \pm 2.01$ (range, 0-5.01) at the end of treatment, and $1.22 \pm 1.73$ (range, $0-4.44$ ) at the end of follow-up (Table 1). The difference between assessment points was not statistically significant for any of these values. Similarly, no significant changes were found between assessment points for the EDE-Q restraint subscale score, which was evaluated separately. The mean CGAS score was $54.8 \pm 8.61$ (range, 40-65) at baseline and 69.13 \pm 21.5 (range, 35-90) at the end of treatment, with no significant post-treatment improvement $(\mathrm{Z}=-1.3, \mathrm{p}=0.21)$. However, as can be seen in Table 1 , there was a significant difference between the mean CGAS score at baseline and that registered at the end of follow-up (80.8, $\mathrm{SD}=10.5$; range, $60-90 ; \mathrm{Z}=-2.5, \mathrm{p}=0.01)$.

Eight families (89\%) attended the final (six-month follow-up) evaluation, seven who had completed the treatment and one who had attended the first session and had then been referred for inpatient treatment. None of the patients examined in the final evaluation met the diagnostic criteria for any eating disorder. Six patients $(67 \%)$ had no symptoms of eating disorders, although two $(22 \%)$ still had symptoms (one had body image distortion, was engaging in excessive exercise and was trying unsuccessfully to restrict food intake; the other had body image dissatisfaction and presented binge eating episodes without compensatory behaviors). None of the eight patients had experienced weight loss or developed amenorrhea.

\section{Discussion}

This is the first examination of FBT for AN in Brazilian adolescents. The feasibility and acceptability is demonstrated by the acceptance rate of the approach (82\%). Of the nine families who started the FBT, 7 (78\%) completed it-one family, of their own accord, declined to participate, and the other was referred to inpatient treatment by the team. FBT also appears to be effective in Brazilian adolescents with $\mathrm{AN}$, in terms of weight recovery, menstrual recovery, and return to normal global functioning as assessed by the CGAS. These findings are consistent with those reported in trials using this approach with similar groups of young adolescents with AN in other cultures. ${ }^{13,14}$ It is noteworthy that most families who participated in the study were compliant with treatment and that all family members participated. This greater compliance might be in part due to the limited number of treatment alternatives or to the high costs of those alternatives. The majority of the patients in our sample belonged to intact families (77.8\%), had at least one sibling (88.9\%) and had the restrictive subtype of AN (100\%), all of which are factors that could have contributed to high compliance and good outcomes.

In our study, the EDE-Q scores steadily improved over the course of our study (from assessment point to assessment point). However, the fact that our study sample was small might have limited the statistical power to detect changes in those measures. In addition, since EDE-Q is a self-report measure and only considerers the responses of the adolescents, participants might have downplayed the severity of symptoms, as has been the case in previous reports. ${ }^{15}$ Other limitations of this study include the use of an observational case series design, the absence of males in the sample, and the lack of a comparison treatment. However, the aim of this pilot study was modest: to demonstrate the practical utility of FBT for adolescents with AN in Brazil. Therefore, even taking these limitations into account, our results support the view that FBT is acceptable, feasible, and effective for Brazilian adolescents with AN. Future studies should be conducted on a larger scale and should compare FBT with the standard treatment in order to identify the moderators of outcome and to calculate relative costs. 


\section{Acknowledgements}

The authors are grateful to Ana Paula Gonzaga, Manoela Nicoletti, and Alicia Cobelo (the therapists involved in the study), as well as to the entire team of the Eating Disorders Outpatient and Inpatient Program at the Universidade de São Paulo Institute of Psychiatry, all of whom contributed to carrying out this study.

\section{Disclosures}

\begin{tabular}{|c|c|c|c|c|c|c|c|}
\hline $\begin{array}{l}\text { Writing group } \\
\text { member }\end{array}$ & Employment & $\begin{array}{l}\text { Research } \\
\text { grant }^{1}\end{array}$ & $\begin{array}{c}\text { Other research grant or } \\
\text { medical continuous } \\
\text { education }\end{array}$ & $\begin{array}{l}\text { Speaker's } \\
\text { honoraria }\end{array}$ & $\begin{array}{c}\text { Ownership } \\
\text { interest }\end{array}$ & $\begin{array}{c}\text { Consultant/ } \\
\text { Advisory } \\
\text { board }\end{array}$ & Other $^{3}$ \\
\hline Gizela Turkiewicz & PROTAD & - & - & - & - & - & - \\
\hline Vanessa Pinzon & PROTAD & - & - & - & - & - & - \\
\hline James Lock & $\begin{array}{l}\text { Stanford } \\
\text { University }\end{array}$ & - & - & - & - & - & - \\
\hline Bacy Fleitlich-Bilyk & $\begin{array}{c}\text { PROTAD } \\
\text { HC-FMUSP }\end{array}$ & - & - & - & - & - & - \\
\hline $\begin{array}{l}\text { * Modest } \\
\text { ** Significant } \\
\text { *** Significant. Amoun } \\
\text { Note: PROTAD = E } \\
\text { Universidade de São }\end{array}$ & $\begin{array}{l}\text { en to the auth } \\
\text { Disorders Ou }\end{array}$ & $\begin{array}{l}\text { istitution o } \\
\text { ent and Ir }\end{array}$ & $\begin{array}{l}\text { colleague for research in } \\
\text { nt Program; HC-FMUSP }\end{array}$ & $\begin{array}{l}\text { Ih the au } \\
\text { Hospital }\end{array}$ & $\begin{array}{l}\text { as particip } \\
\text { Clínicas }\end{array}$ & $\begin{array}{l}\text { not direct } \\
\text { culdade }\end{array}$ & $\begin{array}{l}\text { e al } \\
\text { dicin }\end{array}$ \\
\hline
\end{tabular}

References

1. Hoek HW, van Hoeken D. Review of the prevalence and incidence of eating disorders. Int J Eat Disord. 2003;34(4):383-96.

2. Gowers S, Bryant-Waugh R. Management of child and adolescent eating disorders: the current evidence base and future directions. J Child Psychol Psychiatry. 2004;45(1):63-83.

3. Bulik CM, Berkman ND, Brownley KA, Sedway JA, Lohr KN. Anorexia nervosa treatment: a systematic review of randomized controlled trials. Int $J$ Eat Disord. 2007;40(4):310-20.

4. Lock J, Le Grange D, Agras SW, Dare C. Treatment manual for anorexia nervosa: a family-based approach. New York: The Guilford Press; 2001.

5. Moya T, Fleitlich-Bilyk B. Waiting lists for treatment of eating disorders in childhood and adolescence. Rev Bras Psiquiatr. 2003;25(4): 259-60.

6. Fleitlich-Bilyk B, Goodman R. Prevalence of child and adolescent psychiatric disorders in southeast Brazil. J Am Acad Child Adolesc Psychiatry. 2004; $43(6): 727-34$.

7. Goodman R, Ford T, Richards H, Gatward R, Meltzer H. The Development and Well-Being Assessment: description and initial validation of an integrated assessment of child and adolescent psychopathology. J Child Psychol Psychiatry. 2000;41(5):645-55.

8. Fairburn CG, Beglin SJ. Assessment of eating disorders: interview or self-report questionnaire? Int J Eat Disord. 1994;16(4):363-70.

9. Mond JM, Hay PJ, Rodgers B, Owen C, Beumont PJ. Validity of the Eating Disorder Examination Questionnaire (EDE-Q) in screening for eating disorders in community samples. Behav Res Ther. 2004;42(5):551-67.

10. APA - American Psychiatry Association. Diagnostic and Statistical Manual of Mental Disorders - DSM IV. 2th ed. Washington DC: American Psychiatry Association; 2002.

11. Kuczmarski RJ, Ogden CL, Grummer-Strawn LM, Flegal KM, Guo SS, Wei R, Mei Z, Curtin LR, Roche AF, Johnson CL. CDC growth charts: United States. Adv Data. 2000;314:1-27.

12. Lock J, le Grange D. Family-based treatment of eating disorders. Int J Eat Disord. 2005;37(Suppl):S64-7; discussion S87-9.

13. Lock J, Couturier J, Agras WS. Comparison of long-term outcomes in adolescents with anorexia nervosa treated with family therapy. J Am Acad Child Adolesc Psychiatry. 2006;45(6):666-72.

14. Lock J, Agras WS, Bryson S, Kraemer HC. A comparison of short- and longterm family therapy for adolescent anorexia nervosa. J Am Acad Child Adolesc Psychiatry. 2005;44(7):632-9.

15. Couturier JL, Lock J. Denial and minimization in adolescents with anorexia nervosa. Int J Eat Disord. 2006;39(3):212-6. 